\title{
Analisis faktor-faktor yang mempengaruhi pilihan karir mahasiswa farmasi di Universitas Andalas
}

\author{
Erniza Pratiwi*1 ${ }^{1}$, Deddi Prima Putra ${ }^{2}$, Laura Syahrul ${ }^{3}$ \\ ${ }^{1}$ Sekolah Tinggi Ilmu Farmasi Riau (STIFAR) \\ Jl. Kamboja Simpang Baru Panam, Pekanbaru \\ ${ }^{2}$ Fakultas Farmasi, Universitas Andalas \\ ${ }^{3}$ Fakultas Ekonomi, Universitas Andalas \\ Jl. Limau Manis, Padang
}

Submitted: 13-01-2017

Reviewed: 16-03-2017

Accepted: 24-03-2017

\begin{abstract}
ABSTRAK
Berdasarkan PP 51 tahun 2009 diterangkan bahwa pilihan karir dalam pekerjaan kefarmasian sangatlah beragam. Tujuan penelitian ini adalah untuk menentukan faktor yang paling penting yang mempengaruhi pilihan karir dan pilihan karir utama dari mahasiswa farmasi. Jenis penelitian ini merupakan penelitian deskriptif yang dilakukan dengan menggunakan survey. Teknik pengambilan sampel yang digunakan adalah stratified random sampel. Responden pada penelitian ini sebanyak 85 mahasiswa yaitu mahasiswa tahun pertama, kedua, ketiga dan keempat di Fakultas Farmasi Universitas Andalas. Dari hasil penelitian berdasarkan profil responden, secara keseluruhan mayoritas mahasiswa farmasi memilih berkarir di Industri Farmasi 48,2\%, disusul oleh Rumah Sakit (RS) 35.3\%, University/Research Institute 4,7\%, Apotek 3,5\%, Pedagang Besar Farmasi (PBF) 2,4\%, dan pilihan karir lain-lain (BPOM, departemen kesehatan, kementerian kesehatan dan wiraswasta) mencapai 5,9\%. Berdasarkan hasil analisa data deskriptif, terlihat bahwa lingkungan kerja merupakan kriteria paling penting diantara faktor-faktor yang mempengaruhi pilihan karir mahasiswa farmasi. Kriteria penting terdapat pada faktor-faktor lain yang diteliti secara berurutan yang terdiri atas letak geografis, gaji, jadwal kerja yang fleksibel, kesempatan berkembang dan manfaat. Dari hasil uji beda independent sampel t-test antara jenis kelamin, baik laki-laki maupun perempuan menempatkan tiga faktor utama yang sama dalam mempengaruhi pilihan karir (lingkungan kerja, letak geografis dan gaji) dan variasi terjadi pada faktor keempat, kelima dan keenam. Faktor yang paling penting yang mempengaruhi pilihan karir dari mahasiswa farmasi adalah faktor lingkungan kerja dengan pilihan karir utama adalah industri farmasi.
\end{abstract}

Kata kunci: mahasiswa farmasi, pilihan karir, Universitas Andalas

\begin{abstract}
Based on PP 51 of the year 2009, the pharmaceutical practices have very of choice of carreerfield. The purpose of this research is to determine the most important factor that influence the career choices and the carrier priority choosing of pharmacy students. It was a descriptive study which conducted by survey method by using stratified random sampling. The respondents are 85 students, consisting of $1^{\text {st }}, 2^{\text {nd }}, 3^{\text {rd }}$ and $4^{\text {th }}$ grade students from Faculty of Pharmacy, Andalas University.
\end{abstract}

Penulis korespondesi:

Erniza Pratiwi

Sekolah Tinggi Ilmu Farmasi Riau (STIFAR)

J1. Kamboja Simpang Baru Panam

Email: ernizapratiwi@gmail.com 
The results shown that, in term of the profile of respondent, known that the most of the students choices to work at Pharmaceutical Industry, Hospital, University/Research Institute, pharmacy, pharmacy retail and others career-field (such as BPOM, civil servant at ministry of health and enterpreneur) of $48.2 \%, 35.3 \%, 4.7 \%, 3.5 \% 2.4 \%$ and $5.9 \%$, respectively. Based on the descriptive analysis, it was described that work field was the most important criteria in choosing their future career. The others important criterias those also afforded as the affecting factors were geographis, payment/income, flexibility of work-schedule, possibility of career-development and benefit, successively. The results showed that the independent sample t-test in term of gender (i.e. men and women) showed the same three main affecting factors for choosing the career-field (including field of work, geographis as well as payment/income). However, $4^{\text {th }}, 5^{\text {th }}$ and $6^{\text {th }}$ factors were showed the different results. In this researh, the work field is the most important for the respondents to decide their future choice and the carrier priority choosing from the respondents is to work in the Pharmaceutical Industry.

Keywords: pharmacy students, career choices, Andalas University

\section{PENDAHULUAN}

Sumber Daya Manusia (SDM) dalam sebuah organisasi/perusahaan merupakan asset yang paling berharga, sehingga perlu dikelola secara baik dan profesional agar dapat tercipta keseimbangan antara kebutuhan sumber daya manusia dengan tuntutan pencapaian tujuan organisasi. Salah satu pengelolaan Sumber Daya Manusia (SDM) secara profesional adalah dengan menyelenggarakan pengembangan karir. Untuk mencapai tujuan perusahaan tersebut maka sumber daya manusia perlu diberi dorongan yang cukup agar dapat termotivasi, perlu diberikan penghargaan berupa pengembangan karir, promosi, dan pemberian bonus yang dapat memberikan kepuasan tersendiri bagi karyawan (Yusnita, 2010).

Ruang lingkup pekerjaan kefarmasian serta peran utama dari apoteker telah mengalami perubahan besar. Pada abad ke 20, tanggung jawab apoteker terfokus pada penyiapan dan peracikan obat-obat. Sedangkan pada saat ini, apoteker melaksanakan praktek kefarmasian dalam cakupan profesionalitas yang lebih luas (Keely, 2002). Menurut tradisi, pilihan tempat bekerja bagi apoteker selama ini adalah di Rumah Sakit (RS) atau di apotek, baik apotek perorangan maupun apotek chain. Namun dengan berkembangnya pelayanan kesehatan di masyarakat, maka peluang karir bagi apoteker semakin meluas (Savage et al., 2009).

Di Indonesia menurut peraturan pemerintah Republik Indonesia nomor 51 tahun 2009 tentang pekerjaan kefarmasian, dimana diterangkan bahwa pekerjaan kefarmasian adalah pembuatan obat termasuk pengendalian mutu sediaan farmasi, pengamanan, pengadaan, penyimpanan dan pendistribusian atau penyaluran obat, pengelolaan obat, pelayanan obat atas resep dokter, pelayanan informasi obat, serta pengembangan obat, bahan obat dan obat tradisional. Pilihan karir dalam pekerjaan kefarmasian sangatlah beragam, antara lain rumah sakit, apotek, industri farmasi, pedagang besar farmasi, puskesmas, toko obat, university/research institute, BPOM dan lainnya.

Ada beberapa studi yang telah menilai faktor-faktor yang mempengaruhi bagaimana mahasiswa farmasi membuat pilihan karir mereka, seperti penelitian yang telah dilakukan oleh Savage, Beall dan Woolley (2009) mengenai faktor-faktor yang mempengaruhi pilihan karir mahasiswa Farmasi di Amerika. Penelitian lain yang dilakukan oleh Ubaka et al., (2013) mengenai "Student Pharmacists" Career Choices: a Survey of Three Nigerian Schools of Pharmacy", penelitian yang dilakukan oleh Sarah Caroline Willis, Phil Shann dan Karen Hassell (2009) mengenai "Pharmacy Career Deciding: Making Choice a Good Fit", penelitian oleh Rahman et al., (2001) berjudul "Career Choice of Malaysian Pharmacy Students: A Preliminary Analysis" dan penelitian oleh Shakeel et al., (2013) berjudul "Prospective Career Preferences of Imminent Pharmacist" di Pakistan. Berdasarkan uraian pada latar belakang diatas, maka rumusan masalah pada penelitian ini adalah untuk mengetahui faktorfaktor apa sajakah yang mempengaruhi pilihan karir mahasiswa farmasi di Universitas Andalas. Tujuan penelitian ini adalah untuk menentukam faktor yang paling penting yang mempengaruhi 
pilihan karir dari mahasiswa farmasi Universitas Andalas. Selain itu juga melihat pilihan karir mahasiswa di tahun pertama, kedua, ketiga, dan keempat dari program studi farmasi.

\section{METODELOGI}

Jenis penelitian ini merupakan penelitian deskriptif yang dilakukan dengan menggunakan survey yang dilengkapi dengan kuesioner dan pertanyaan terbuka. Penelitian ini menggunakan metode analisis deskriptif dan uji beda independent sampel t-test. Hasil analisis di rangkum dalam bentuk tabel dan gambar yang memuat seluruh variabel penelitian yang telah disesuaikan dengan standar dan rujukan penelitian terdahulu.

\section{Populasi dan sampel penelitian}

Dalam penelitian ini yang menjadi populasi adalah seluruh Mahasiswa Farmasi tahun pertama, kedua, ketiga dan keempat yang berjumlah 554 orang. Responden pada penelitian ini yaitu sebanyak 85 orang yang terdiri dari mahasiswa tahun pertama 21 orang , tahun kedua 22 orang, tahun ketiga 24 orang dan tahun keempat 18 orang. Teknik pengambilan sampel yang digunakan adalah stratified random sampel (cara stratifikasi) dikarenakan dalam penelitian ini pada populasi terdapat strata dari anggotanya, maka pada setiap strata harus terwakili dalam sampel.

\section{Pengolahan dan analisis data}

Pengumpulan data diawali dengan mendeskripsikan profil responden yang terdiri dari jenis kelamin, umur, dan pilihan karir. Selanjutnya dilakukan uji validitas dan reliabilitas serta distribusi frekwensi jawaban responden terhadap masing-masing butir pertanyaan yang digunakan untuk mengukur variabel penelitian dalam penelitian ini yaitu gaji, jadwal kerja yang fleksibel, manfaat, letak geografis, kesempatan berkembang dan lingkungan kerja. Selanjutnya dari hasil pengumpulan data dilakukan analisis deskriptif, Tingkat Capaian Responden (TCR) dan uji beda independent sampel t-test untuk mengetahui faktor-faktor yang mempengaruhi pilihan karir mahasiswa farmasi.

\section{HASIL DAN PEMBAHASAN}

Dari hasil survei diperoleh responden mahasiswa farmasi sebanyak 85 orang yang terdiri dari mahasiswa tahun pertama, kedua, ketiga, dan keempat. Penelitian ini dilakukan di Fakultas Farmasi Universitas Andalas Padang yang dilaksanakan pada bulan Juni-Desember 2013. Dari hasil profil responden yang diperoleh didapatkan bahwa mayoritas responden adalah perempuan dan bila dilihat dari sisi umur, responden terdistribusi hampir sama dan tidak terlalu berbeda. Berdasarkan hasil pengolahan data, sebaran pilihan karir mahasiswa farmasi ternyata terkonsentrasi hanya pada 2 pilihan karir yaitu : industri farmasi $48,2 \%$ dan rumah sakit $35,3 \%$.

\section{Pengujian instrumen penelitian}

Pengujian instrumen penelitian yaitu dengan uji validitas dan reliabilitas yang dilakukan terhadap semua item pernyataan yang digunakan. Hasil uji validitas dan reliabilitas penelitian menunjukkan bahwa semua item pernyataan yang digunakan sebagai instrumen penelitian hasilnya valid dan dapat digunakan untuk analisa data berikutnya. Hasil uji reliabilitas menyatakan bahwa variabel yang digunakan dalam penelitian adalah reliabel/handal dan dapat dilihat dari nilai cronbach's alpha lebih besar dari 0,60 .

\section{Pilihan karir mahasiswa farmasi berdasarkan faktor-faktor yang mempengaruhi}

Berdasarkan uraian persepsi responden mengenai tingkat pentingnya masing-masing variabel yang mempengaruhi pilihan karir mereka kedepan, maka secara keseluruhan dapat dilihat/digambarkan pada Tabel III. 
Tabel I. Profil responden

\begin{tabular}{cccc}
\hline Uraian & Kategori & $\begin{array}{c}\text { Frekuensi } \\
(\text { orang) }\end{array}$ & $\begin{array}{c}\text { Persentase } \\
(\boldsymbol{\%})\end{array}$ \\
\hline \multirow{2}{*}{ Jenis kelamin } & Laki-laki & 13 & 15.3 \\
& Perempuan & 72 & 84.7 \\
\multirow{2}{*}{ Umur } & 18 tahun & 24 & 28.2 \\
& 19 tahun & 17 & 20.0 \\
& 20 tahun & 25 & 29.4 \\
& 21 tahun & 15 & 17.6 \\
& 22 tahun & 4 & 4.7 \\
\hline
\end{tabular}

Tabel II. Profil responden berdasarkan pilihan karir

\begin{tabular}{|c|c|c|c|c|c|c|c|c|c|c|}
\hline \multirow{3}{*}{ Pilihan Karir } & \multicolumn{10}{|c|}{ Mahasiswa / Angkatan } \\
\hline & \multicolumn{2}{|c|}{$\begin{array}{c}\text { Tahun } \\
2013\end{array}$} & \multicolumn{2}{|c|}{ Tahun 2012} & \multicolumn{2}{|c|}{ Tahun 2011} & \multicolumn{2}{|c|}{$\begin{array}{c}\text { Tahun } \\
2010\end{array}$} & \multicolumn{2}{|c|}{$\begin{array}{c}\text { Total } \\
\text { Mahasiswa/ } \\
\text { Pilihan Karir }\end{array}$} \\
\hline & $\mathbf{F}$ & $\%$ & $\mathbf{F}$ & $\%$ & $\mathbf{F}$ & $\%$ & $\mathbf{F}$ & $\%$ & $\mathbf{F}$ & $\%$ \\
\hline University/ & 0 & 0 & 1 & 4.5 & 0 & 0 & 3 & 16.7 & 4 & 4.7 \\
\hline Research Institute & & & & & & & & & & \\
\hline Industri Farmasi & 17 & 81 & 10 & 45.5 & 9 & 37.5 & 5 & 27.8 & 41 & 48.2 \\
\hline Rumah Sakit & 2 & 9.5 & 8 & 36.4 & 10 & 41.7 & 10 & 55.5 & 30 & 35.3 \\
\hline PBF & 0 & 0 & 0 & 0 & 2 & 8.3 & 0 & 0 & 2 & 2.4 \\
\hline Apotek & 2 & 9.5 & 1 & 4.5 & 0 & 0 & 0 & 0 & 3 & 3.5 \\
\hline Lain - lain & 0 & 0 & 2 & 9.1 & 3 & 12.5 & 0 & 0 & 5 & 5.9 \\
\hline Total Responden & 21 & 100 & 22 & 100 & 24 & 100 & 18 & 100 & 85 & 100 \\
\hline
\end{tabular}

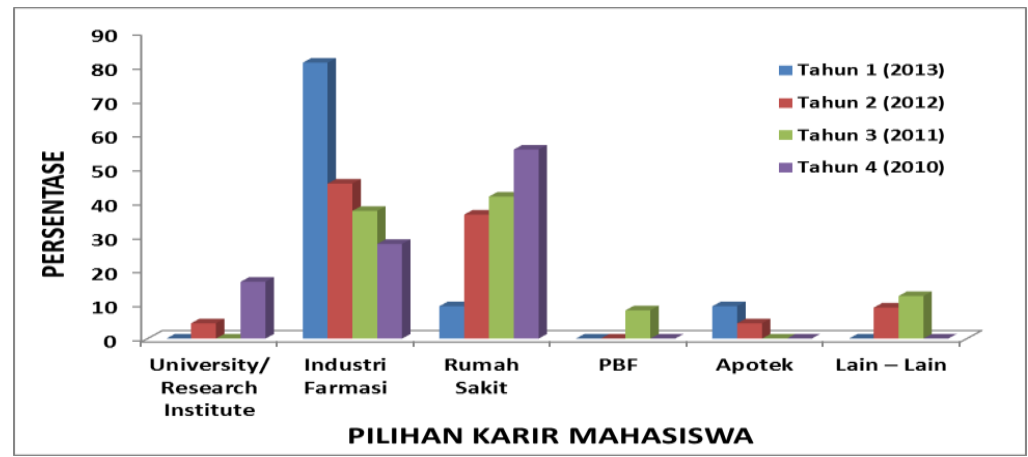

Gambar 1. Grafik Pilihan Karir Mahasiswa Farmasi Berdasarkan Angkatan

Tabel III. Pilihan karir berdasarkan tingkat penting variable

\begin{tabular}{lcc}
\hline \multicolumn{1}{c}{ Variabel } & Tingkat Penting Variabel & Keterangan \\
\hline Lingkungan Kerja & 92.4 & Sangat Penting \\
Letak Geografis & 89.4 & Penting \\
Gaji / Pendapatan & 87.8 & Penting \\
Jadwal Kerja yang Fleksibel & 86.4 & Penting \\
Kesempatan Berkembang & 86.1 & Penting \\
Manfaat & 84.5 & Penting \\
\hline
\end{tabular}


Berdasarkan hasil analisa data, Tingkat Capaian Responden (TCR) yang diperoleh dari 6 variabel termasuk dalam kriteria penting dan sangat penting. Kriteria sangat penting terdapat pada variabel lingkungan kerja sebesar 92,4\%, dimana variabel ini menempati urutan pertama dalam mempengaruhi pilihan karir mahasiswa farmasi. Kriteria penting terdapat pada faktor-faktor lain yang diteliti yang terdiri atas gaji/ pendapatan, jadwal kerja yang fleksibel, manfaat, letak geografis dan kesempatan berkembang dengan presentase berkisar antara 84,5\% - 89,4\%. Variabel letak geografis menempati urutan kedua terpenting dalam pemilihan karir mahasiswa farmasi kedepannya.

\section{Hasil pengujian beda independent sample T-Test}

Untuk melihat adanya pengaruh demografi terhadap pentingnya variabel yang mempengaruhi pilihan karir responden, maka dilakukan uji Beda dengan hasil yang dapat dilihat pada Tabel IV.

Tabel IV. Hasil uji beda independent sample T- Test

\begin{tabular}{lccccccc}
\hline Demografi & Jumlah & Gaji & $\begin{array}{c}\text { Jadwal } \\
\text { Kerja } \\
\text { Fleksibel }\end{array}$ & Manfaat & $\begin{array}{c}\text { Letak } \\
\text { Geografis }\end{array}$ & $\begin{array}{c}\text { Kesempatan } \\
\text { Berkembang }\end{array}$ & $\begin{array}{c}\text { Lingkungan } \\
\text { Kerja }\end{array}$ \\
\hline Jenis Kelamin & & Mean & Mean & Mean & Mean & Mean & Mean \\
Laki-laki & 13 & 4.54 & 4.08 & 4.38 & 4.69 & 4.41 & 4.73 \\
Perempuan & 72 & 4.37 & 4.36 & 4.20 & 4.43 & 4.29 & 4.60 \\
Angkatan & & & & & & & 4.64 \\
Tahun 2013 & 21 & 4.37 & 4.43 & 4.30 & 4.43 & 49 & 4.73 \\
Tahun 2012 & 22 & 4.42 & 4.50 & 4.27 & 4.32 & 4.38 & 4.44 \\
Tahun 2011 & 24 & 4.38 & 4.04 & 4.15 & 4.46 & 4.16 & 4.71 \\
Tahun 2010 & 18 & 4.41 & 4.33 & 4.19 & 4.72 & 4.30 & \\
\hline
\end{tabular}

Responden berdasarkan jenis kelamin, lingkungan kerja merupakan faktor yang dinilai paling penting dalam pemilihan karir baik mahasiswa laki-laki maupun perempuan. Sementara diurutan kedua dan ketiga baik laki-laki maupun perempuan sama-sama menempatkan faktor letak geografis dan diikuti faktor gaji. Pada urutan keempat terdapat perbedaan dimana laki-laki menempatkan kesempatan berkembang dan perempuan menempatkan jadwal kerja yang fleksibel. Begitu juga halnya untuk faktor urutan lima dan enam dari segi penting atau tidak penting.

Dapat dilihat bahwa perempuan menempatkan kesempatan berkembang pada urutan kelima sementara laki-laki menempatkan manfaat pada urutan yang sama. Dari hasil pengolahan data juga terbaca bahwa yang paling kurang penting dari keenam faktor yang diteliti bagi perempuan adalah manfaat, sementara bagi laki-laki adalah jadwal kerja yang fleksibel. Berdasarkan angkatan terlihat bahwa lingkungan kerja masih menjadi prioritas dihampir seluruh angkatan. Sementara faktor-faktor lain tidak terlalu memperlihatkan perbedaan yang berarti.

Bila dilihat berdasarkan tahun ajaran/angkatan, maka pilihan karir mahasiswa farmasi pada angkatan tahun pertama (2013) sebagian besar lebih tertarik ke industri farmasi yaitu sebesar $81 \%$. Namun dengan berjalannya proses perkuliahan terjadi kecenderungan penurunan secara konsisten sehingga pilihan karir pada industri farmasi tidak lagi menjadi pilihan utama. Untuk pilihan karir di Rumah Sakit, justru terjadi hal sebaliknya dimana mahasiswa pada angkatan tahun pertama (2013) ternyata hanya $9,5 \%$ yang memilih berkarir di rumah sakit. Namun dengan berjalannya waktu studi, dari tahun ke tahun terjadi kecenderungan peningkatan yang konsisten terhadap pilihan ini sehingga di tahun keempat rumah sakit menjadi pilihan utama mahasiswa. Hasil penelitian ini konsisten dengan hasil penelitian yang dilakukan oleh Hassan et al., (2010) yang berjudul "Influences on Malaysian Pharmacy Students' Career Preferences", yang mengemukakan bahwa mahasiswa tingkat akhir di perguruan tinggi negeri Malaysia lebih tertarik pada pelayanan farmasi rumah sakit sebagai langkah karir pertama mereka setelah lulus. Penelitian lain yang dilakukan oleh Ubaka et al., (2013) mengenai "Student Pharmacists' Career Choices: a Survey of Three Nigerian Schools of Pharmacy", 
menunjukkan bahwa mahasiswa farmasi memilih rumah sakit sebagai pilihan karir mereka di masa depan, dengan pertimbangan dapat melaksanakan pelayanan kesehatan pasien rawat inap dan interaksi sehari-hari dengan tenaga kesehatan lainnya.

Hasil penelitian ini juga konsisten dengan penelitian yang dilakukan oleh Shakeel et al., (2013) berjudul "Prospective Career Preferences of Imminent Pharmacist" di Pakistan, yang mengemukakan bahwa farmasi rumah sakit adalah pilihan karir yang diinginkan mahasiswa farmasi di masa depan untuk memulai karir mereka. Mendapatkan kesempatan untuk menjadi bagian dari tim kesehatan dan memanfaatkan pengetahuan mereka adalah alasan utama untuk memilih karir tertentu dari praktik farmasi. Industri farmasi dan farmasi rumah sakit adalah pilihan karir yang paling mereka sukai untuk memulai karir di masa depan.

Pemberian materi selama masa studi kepada seluruh mahasiswa farmasi telah terdistribusi merata, dimana keseluruhan materi di bidang farmasi telah diajarkan selama masa studi ditiap tahunnya. Faktor eksternal sangat mempengaruhi pilihan karir mahasiswa farmasi di tahun pertama, kedua, ketiga dan keempat. Lingkungan sosial budaya masyarakat, pergaulan teman sebaya, pengaruh dari seluruh anggota keluarga besar dan faktor eksternal lainnya sangat mempengaruhi mahasiwa farmasi dalam pemilihan karir kedepannya.

Pada bagian berikut ini pembahasan dilakukan mengenai faktor-faktor yang mempengaruhi pilihan karir mahasiswa farmasi sesuai dengan urutan faktor yang dinilai sangat penting oleh mahasiswa berdasarkan hasil pengolahan data.

\section{Lingkungan kerja (Work Environment)}

Hasil penelitian menunjukkan bahwa lingkungan kerja dinilai "sangat penting" oleh responden baik laki-laki maupun perempuan dan menduduki urutan pertama sebagai faktor yang dipertimbangkan dalam pilihan karir mereka. Hasil penelitian ini sejalan dengan penelitian yang dilakukan oleh Savage, Beall dan Woolley (2009) dalam penelitian mengenai faktor-faktor yang mempengaruhi pilihan karir mahasiswa Farmasi di Amerika.

Kondisi lingkungan kerja yang baik apabila karyawan dapat melaksanakan kegiatan secara optimal, sehat, aman dan nyaman. Responden menginginkan lingkungan kerja yang aman, sehingga mereka bisa bekerja dengan baik dan lingkungan kerja yang aman bisa menekan keinginan karyawan untuk resign dari institusi kerja. Apabila lingkungan kerja tidak aman akan dapat menurunkan motivasi serta semangat kerja dan akhirnya dapat menurunkan kinerja karyawan.

Sangat pentingnya lingkungan kerja menunjukkan besarnya harapan mereka terhadap keamanan kerja dalam pekerjaan yang dipilih nantinya baik terkait dengan sarana, prasarana serta prosedur yang mendukung. Hal ini terkait dengan kesadaran akan besarnya resiko kerja dibidang farmasi yang tergolong tinggi.

\section{Letak geografis (Geographic Location)}

Hasil penelitian memperlihatkan bahwa faktor letak geografis dipilih oleh baik responden lakilaki maupun perempuan sebagai faktor diurutan kedua dengan kategori penting. Dalam banyak penelitian yang berkaitan dengan karir perempuan, factor sosio cultural masih sangat berperan bagi perempuan dalam memutuskan pilihan karir. Perempuan cenderung lebih memilih bekerja dilingkungan yang tidak jauh agar masih dapat melaksanakan peran gandanya. Perempuan Indonesia yang bekerja masih terkungkung stereotype dan membuat mereka takut melanggar norma sosial yang ditetapkan masyarakat agar perempuan terlebih dahulu mengatasi urusan keluarga, suami, anak dan hal lain yang menyangkut kehidupan rumah tangga (Seniati, 2002). Perempuan dituntut untuk mampu menyeimbangkan peran gandanya agar tidak terjadi konflik kerja-keluarga (Koppelman, 1983 dan Adams, 1996).

Namun letak geografis ini ternyata juga terlihat pada laki-laki. Mengingat secara budaya tidak ada tuntutan peran ganda bagi laki-laki maka satu hal yang menarik untuk diamati adalah kaitannya dengan hasil pengolahan data yang memperlihatkan rendahnya keinginan responden untuk hal-hal yang bersifat menantang di dunia kerja. Hasil penelitian ini didukung oleh penelitian yang dilakukan 
oleh Ubaka et al., (2013) di Nigerian, yang mengemukakan bahwa mayoritas mahasiswa farmasi perempuan lebih mempertimbangkan letak geografis dalam pemilihan karir di masa depan, berbeda dengan pendapat mahasiswa laki-laki.

\section{Gaji (Salary)}

Gaji menduduki urutan ketiga sebagai faktor yang dipertimbangkan dalam menentukan pilihan karir. Berdasarkan jenis kelamin, baik responden laki-laki maupun perempuan menempatkan gaji pada urutan ketiga setelah lingkungan kerja dan letak geografis. Responden sangat memperhatikan gaji/pendapatan di institusi kerja mereka nantinya dalam mempertimbangkan pilihan karir dan menginginkan agar mereka mendapatkan gaji minimal sesuai dengan standar yang berlaku di pasar tenaga kerja.

Mengingat mayoritas responden adalah perempuan, hasil penelitian ini memperlihatkan suatu kecendrungan baru yang relative berbeda bila dikaitkan dengan penelitian tentang perempuan bekerja terdahulu khususnya di Indonesia dimana laki-laki adalah "Bread winner" sedang perempuan hanya sebagai pencari nafkah tambahan yang tidak terlalu mempertimbangkan soal gaji (Sayogyo, 1985). Hasil penelitian ini didukung oleh penelitian yang dilakukan oleh Puspitasari et al., (2013) yang mengemukakan bahwa sudah banyak istri yang bekerja di sektor publik yang menghasilkan uang untuk menambah penghasilan keluarga. Hal ini dilakukan untuk menghadapi tekanan ekonomi dan kebutuhan rumah tangga. Semakin baiknya tingkat pendidikan dan kompetensi khusus yang dimiliki perempuan diyakini menjadi hal yang turut mempengaruhi orientasi mereka terhadap apa yang menjadi penting dalam pilihan karir.

\section{Jadwal kerja yang fleksibel (Flexible Work Schedule)}

Jadwal kerja yang fleksibel menempati urutan keempat sebagai faktor yang dipertimbangkan dalam pilihan karir kedepan. Responden menginginkan adanya jadwal kerja yang fleksibel di institusi kerja. Hasil ini masih sangat relevan dengan konsep peran ganda perempuan. Tuntutan peran untuk memberi perhatian pada suami yang cukup dan peran dalam tumbuh kembang anak memberi tekanan psikologis sehingga memilih pekerjaan dengan waktu yang fleksibel, bilamana mungkin (Widyaningrum et al., 2013). Namun bila dibedakan antar jenis kelamin, faktor jadwal kerja yang fleksibel ini berada di urutan paling akhir bagi responden laki-laki. Hal ini bukan menjadi pertimbangan penting.

Hasil penelitian ini didukung oleh penelitian yang dilakukan oleh Ubaka et al., (2013) di Nigerian, mengemukakan bahwa mayoritas mahasiswa farmasi perempuan lebih mempertimbangkan adanya jadwal kerja yang fleksibel dalam pemilihan karir di masa depan, berbeda dengan pendapat mahasiswa laki-laki.

\section{Kesempatan berkembang (Advancement Opportunities)}

Kesempatan berkembang menempati urutan kelima sebagai faktor yang dipertimbangkan dalam pilihan karir kedepan. Responden menginginkan adanya kesempatan perkembangan karir mereka kedepannya, sehingga mereka dapat menambah pengetahuan dan mengembangkan kemampuan yang mereka miliki. Dalam penelitian yang dilakukan oleh Savage, Beall dan Woolley (2009) mengatakan bahwa $42 \%$ kesempatan berkembang di institusi kerja berperan penting dalam mempengaruhi pilihan karir. Institusi kerja hendaknya memberikan kesempatan berkembang kepada karyawan untuk meningkatkan kemampuan, misalnya melalui pelatihan-pelatihan, kursus, dan melanjutkan pendidikannya. Hal ini akan memberikan karyawan kesempatan untuk tumbuh dan berkembang sesuai dengan rencana karirnya.

Responden menginginkan pengembangan profesi mereka nantinya sebagai tenaga kesehatan yaitu Apoteker dan Tenaga Teknis Kefarmasian. Dalam pengembangan karir responden mengungkapkan bahwa perlu adanya otonomi profesi, sehingga mereka bisa melakukan pekerjaan mereka sesuai dengan hak dan kewajiban mereka di institusi kerja sesuai dengan peraturan pemerintah Republik Indonesia nomor 51 tahun 2009.

Manfaat (Benefits) 
Manfaat menempati urutan keenam sebagai faktor yang dipertimbangkan dalam pilihan karir kedepan. Responden sangat mempertimbangkan manfaat apa saja yang akan mereka terima/dapatkan dari institusi kerja nantinya. Dari hasil pengolahan data juga terbaca bahwa yang paling kurang penting dari keenam faktor yang diteliti bagi perempuan adalah manfaat, berbeda dengan laki-laki. Dapat bekerja di institusi yang bergengsi, dengan banyaknya tantangan dalam bekerja, serta mendapatkan posisi yang dihormati adalah harapan/keinginan responden.

Menurut penelitian yang dilakukan oleh Savage, Beall dan Woolley (2009) mengatakan bahwa $53,3 \%$ manfaat yang diperoleh dari institusi kerja sangat berperan penting dalam mempengaruhi pilihan karir. Pendapat responden terhadap manfaat didukung oleh hasil pertanyaan terbuka dimana menempatkan "Fasilitas yang cukup" merupakan alasan bagi mereka dalam pemilihan karir mendatang.

\section{KESIMPULAN}

Penelitian ini menggunakan instrumen penelitian yang telah teruji valid dan handal. Dengan metoda deskriptif, temuan utama penelitian ini dimana terdapat variasi konsentrasi pilihan karir mahasiswa farmasi dengan pilihan utama ada pada Industri Farmasi yang mencapai 48,2\% dan diikuti oleh Rumah Sakit (RS) 35,3\%. Faktor lingkungan kerja merupakan faktor yang dinilai sangat penting bagi mahasiswa farmasi dalam mempertimbangkan pilihan karir ke depan. Beberapa faktor lain yang diteliti hanya masuk dalam kategori penting dengan urutan berdasarkan tingginya tingkat "penting" tersebut adalah letak geografis, gaji/pendapatan, jadwal kerja yang fleksibel, kesempatan berkembang, dan manfaat. Dari hasil uji beda antara jenis kelamin, baik laki-laki maupun perempuan menempatkan tiga faktor utama yang sama. Variasi terjadi pada faktor keempat, kelima dan keenam. Faktor yang mempengaruhi pilihan karir berdasarkan angkatan ternyata tidak memperlihatkan perbedaan yang berarti.

\section{KETERBATASAN PENELITIAN}

Sekalipun telah menggunakan literatur dan studi empiris terdahulu, semua penelitian memiliki keterbatasan yang memberi arah bagi penelitian lain ke depan. Penelitian ini hanya mengkaji pilihan karir serta faktor-faktor yang mempengaruhi pilihan karir mahasiswa farmasi saja. Hal ini memungkinkan bagi peneliti selanjutnya untuk meneliti berbagai variabel individual serta variabel lingkungan eksternal yang mempengaruhi agar diperoleh gambaran yang lebih komprehensif dan memberi kontribusi bagi upaya perubahan dan penyempurnaan institusi ke depan. Disamping itu penelitian ini dilakukan pada Universitas Andalas yang merupakan salah satu dari universitas yang ada di Indonesia. Latar belakang mahasiswa, lingkungan, kebijakan kampus yang berbeda memungkinkan hasil yang berbeda pula. Untuk itu peluang bagi peneliti selanjutnya untuk mengkaji pilihan karir serta faktor yang mempengaruhinya dalam sekala yang lebih luas.

\section{DAFTAR PUSTAKA}

Adams, G. A., King, L. A., King, D. W., 1996, Relationship of Job and family Involvement, Family Social Support and Work-Family Conflict With Job and Life Satisfaction. J App Psy. 81: 411420.

Hasan, S.S., Chong, D.W.K., Ahmadi,K., Se, W.P., Hassali, M.A., Hata, E.M., Hadi, M.A., Sridhar, S.B., Ahmed, S.I., Yean, L.B., Efendie, B., 2010, Influences on Malaysian Pharmacy Student's Career Preferences. Am J Pharm Educ, 74(9): 166.

Keely, J.L., 2002, Pharmacist Scope of Practice. Ann Intern Med. 136: 79-85.

Kopelman, R. E., Greenhaus, J. H., Connolly, T. F., 1983, A Model of Work Family and Internal Conflict: A Construct Validation Study. J Org Behav Hum Perform. 32: 198-215.

Puspitasari, N., Puspitawati, H., Herawati, T., 2013. Peran Gender, Kontribusi Ekonomi Perempuan dan Kesejahteraan Keluarga Petani Hortikultura, Jur. IIm. Kel. dan Kons, 6(1): 10-19.

Rahman, A. F. A., Ibrahim, M. I. M., Yusoff, Z. M., Bahari, M. B. dan Ismail, R., 2001, Career Choice of Malaysian Pharmacy Students: A Preliminary Analysis. Mal J Pharm,1(1). 
Sajogyo, P., 1985, Peranan Wanita Dalam Perkembangan Masyarakat Desa, Jakarta, Rajawali.

Savage, L.M., Beall, J.W., Woolley, T.W., 2009, Factors That Influence the Career Goals of Pharmacy Students. Am J Pharm Educ. 73(2): 28.

Seniati, L., Dahesihsari, R., 2002, Hubungan Antara Peran Gender, Fear of Success dan Kesukubangsaan dengan Komitmen Dosen Perempuan Terhadap Organisasi. J Psy Anima Indonesian. 17: 332-345.

Shakeel, S., Iffat, W., Yasmin, R., Ali, H., 2013, Prospective Career Preferences of Imminent Pharmacist. IOSR J Pharm. 3(8): 38-43.

Ubaka, C.M., Ochie, U. M., Adibe, M.O., 2013, Student Pharmacist's Career Choices: a Survey of Three Nigerian Schools of Pharmacy. Pharmacy Practice. 11(3): 149-155.

Widyaningrum, I.A., Pongtuluran, Y., Tricahyadinata, I., 2013, Pengaruh Konflik Peran Ganda dan Stress Kerja Terhadap Kinerja Karyawan Wanita pada Swalayan Era Mart 5000 di Samarinda. Samarinda: Universitas Mulawarman.

Willis, S. C., Shann, P. dan Hassell, K. 2009, Pharmacy Career Deciding: Making Choice a "Good Fit". J Health Org Manage. 23(1): 85-102.

Yusnita, R.T., 2010, Pengaruh Pengembangan Karir Terhadap Konflik Pekerjaan-Keluarga dan Ketakutan Akan Kesuksesan pada Wanita Serta Dampaknya pada Prestasi Kerja. Tasikmalaya: Survey Pemerintah Kota Tasikmalaya. 
